Supporting Information

\title{
Facile, Fast-Responsive and Photostable Imaging of Telomerase Activity in Living Cells with a Fluorescence Turn-on Manner
}

Yuan Zhuang, Fujian Huang, Qi Xu, Mengshi Zhang, Xiaoding Lou* and Fan Xia

Hubei Key Laboratory of Bioinorganic Chemistry \& Materia Medica, School of Chemistry and Chemical Engineering, Huazhong University of Science and Technology, Wuhan 430074, P. R. China

* To whom correspondence should be addressed: louxiaoding@ hust.edu.cn 


\section{Table of Contents:}

\section{Experimental Section}

1.1 Synthesis of TPE-Py

1.2 Cell Culture

1.3 Telomerase Extension Reaction

1.4 Telomerase Activity Detection by TPE-Py

1.5 Specificity Study

1.6 Investigation of Telomerase Inhibition.

1.7 Assay of S1 Nase Degradation

1.8 Non-Denaturating Polyacrylamide Gel (PAGE) Analysis

1.9 Telomerase Activity Detection Using a Commercial ELISA Kit

\section{Figures \& Tables}

\subsection{Mechanism Study}

Table S1. Oligonucleotides used in this study

Figure S1. Fluorescence spectra in response to E-J, HeLa, and MCF-7 cancer cells

Figure S2. Inhibition of telomerase activity by EGCG, SODN, and ASODN

Figure S3. Fluorescence spectra in the presence of S1 Nase

Figure S4. Non-denaturating PAGE analysis

Figure S5. Mechanism study by a commercial human telomerase ELISA Kit

\subsection{Transfection Verification}

Figure S6. Confocal images of E-J cells after transfection with NBD-primer

\subsection{In Situ Detection of Telomerase Activity}

Figure S7. Parallel confocal images (using QP) of E-J, T24, HeLa, MCF-7, HepG2, and HLF cells

Table S2. Fluorescence enhancement ratios (using QP) of different cancer cells

\subsection{Photobleaching Telorance}

Figure S8. Time course images of E-J cells after TPE-Py or LysoTracker dyed

\subsection{In Situ Tracking of Intracellular Telomerase Activity Using Different Types of}

\section{Cells}

Figure S9. Time course of confocal merge images of MCF-7 cells

Figure S10. Time course of confocal images of E-J cells

Figure S11. Time course of confocal images of HeLa cells

\subsection{Probe Stability and Intracellular Working Mechanism}

Figure S12. Confocal images (using TP) of E-J, T24, HeLa, and HLF cells

Table S3. Fluorescence enhancement ratios (using TP) of different cancer cells

Figure S13. Confocal images of E-J cells after transfection with unordered primer or without dyeing

Figure S14. Confocal images of E-J cells inhibited by SODN and ASODN

\section{Reference}




\section{Experimental Section}

\subsection{Synthesis of TPE-Py}

4-\{2-[4-(1,2,2-triphenylvinly)phenyl]vinyl\}-1-methylpyridinium

hexafluorophosphate (TPE-Py) was synthesized according to the previous literature ${ }^{1}$.

\subsection{Cell Culture}

Cells were cultured in appropriate medium with $10 \%$ fetal calf serum (FBS) and $1 \%$ penicillin streptomycin (10000 IU penicillin and $10000 \mu \mathrm{g} / \mathrm{mL}$ streptomycin, Multicell) in a culture flask at $37^{\circ} \mathrm{C}$ in a humidified atmosphere containing $5 \% \mathrm{CO}_{2}$. The media were minimum essential medium (MEM/EBSS, 1X, HyClone) for E-J cancer cells, T24 cancer cells and HLF cells, Dulbecco's modified Eagle's medium (DMEM, Multicell) for MCF-7 and HepG2 cancer cells, and 1640 medium (Gibco) for HeLa cancer cells.

\subsection{Telomerase Extension Reaction}

Telomerase extension reaction was conducted according to the steps below:

A certain volume of telomerase extracts from cancer or normal cells was mixed with dNTPs, RRI, and Quencher group labeled TS primer (QP). In addition of appropriate volume of telomerase extension reaction buffer, the solution was incubated at $37{ }^{\circ} \mathrm{C}$ for $60 \mathrm{~min}$ to react, then put into $94{ }^{\circ} \mathrm{C}$ for $10 \mathrm{~min}$ to end the reaction. The whole reaction was conducted under the condition of protection from light.

\subsection{Telomerase Activity Detection by TPE-Py}

After reaction, TPE-Py was added to solution with the final concentration as $5 \mu \mathrm{M}$ and total volume as $200 \mu \mathrm{L}$, respectively. The final concentration of QP was $0.5 \mu \mathrm{M}$. Then the fluorescence detection was carried out on a Cary Eclipse Fluorescence Spectrophotometer (Agilent Technologies). Excitation wavelength: 403 nm; emission wavelength: from 450 to $700 \mathrm{~nm}$.

\subsection{Specificity Study}

In the specificity experiments, a variety of interferents including lysis buffer, trypsin, thrombin, BSA, Bst DNA polymer, ATP, GSH, lipofectamine 2000, and miR-21 were used in place of telomerase to carry out the extension reaction. The volumes of lysis buffer, trypsin, and lipofectamine added to the mixture solution were the same as telomerase. The concentration was $10 \mathrm{nM}$ for thrombin, $10.0 \mathrm{mg} / \mathrm{L}$ for BSA, $16 \mathrm{U}$ for Bst DNA polymer, $3 \mathrm{mM}$ for ATP, $10 \mathrm{mM}$ for $\mathrm{GSH}$, and $0.5 \mu \mathrm{M}$ for miR-21.

\subsection{Investigation of Telomerase Inhibition.}

In the telomerase inhibition experiments, $1 \mathrm{mM}$ AZT ( $1 \mathrm{mM} \mathrm{EGCG}, 0.5 \mu \mathrm{M}$ SODN or $0.5 \mu \mathrm{M}$ ASODN) and telomerase extracts from 10000 E-J cancer cells were co-incubated at $37^{\circ} \mathrm{C}$ for $30 \mathrm{~min}$. Then, appropriate volume of as-prepared telomerase was added into the telomerase extension reaction to investigate the inhibition usage.

\subsection{Assay of S1 Nase Degradation}

Telomerase extension reaction was conducted as described above. After incubation at $37^{\circ} \mathrm{C}$ for $60 \mathrm{~min}$ and $95{ }^{\circ} \mathrm{C}$ for $10 \mathrm{~min}$, TPE-Py was added to solution with final concentration of $5 \mu \mathrm{M}$ and total volume of $200 \mu \mathrm{L}$. Fluorescence spectrum was 
measured on fluorescence spectrophotometer. Subsequently, 18 U S1 Nase was added into the solution, then the mixture was incubated at $37^{\circ} \mathrm{C}$ for $10 \mathrm{~min}$ and $95^{\circ} \mathrm{C}$ for 10 min. After fluorescence spectrum measurement, another $18 \mathrm{U} \mathrm{S} 1$ Nase was added into the solution for the second time before incubation at $37^{\circ} \mathrm{C}$ for $10 \mathrm{~min}$ and $95{ }^{\circ} \mathrm{C}$ for $10 \mathrm{~min}$. Then fluorescence spectrum was measured again.

\subsection{Non-Denaturating Polyacrylamide Gel (PAGE) Analysis}

Telomerase extracts from 50000 E-J cells, 50000 HeLa cells and 50000 MCF-7 cells were incubated with $2.3 \mathrm{mM}$ dNTPs, $4.65 \mu \mathrm{M}$ QP and $20 \mathrm{U}$ RRI in telomerase extension reaction buffer with the total volume of $21.5 \mu \mathrm{L}$ at $37{ }^{\circ} \mathrm{C}$ for $60 \mathrm{~min}$. Control experiment was treated similarly except telomerase. A $10 \%$ non-denaturing PAGE analysis of $5 \mu \mathrm{L}$ mixture and $1 \mu \mathrm{L} 6 \mathrm{X}$ loading buffer was carried out in $1 \mathrm{X}$ TEB buffer at $90 \mathrm{~V}$ constant voltage for $\sim 2 \mathrm{~h}$. Then the gel was stained with $3 \mathrm{X}$ Gel Red (10000 X $\mathrm{H}_{2} \mathrm{O}$, Biosharp) in $50 \mathrm{~mL} 1 \mathrm{X}$ TBE buffer (TaKaRa Bio Inc.) for $30 \mathrm{~min}$ and imaged by Gel-Pro Transilluminator 2020D (Carestream Health).

\subsection{Telomerase Activity Detection Using a Commercial ELISA Kit}

The human telomerase (TE) ELISA Kit (Shanghai Qiaodu Biotechnology Co., Ltd) experiment was carried out according to the instruction. Briefly, a relative standard curve was performed using standard telomerase activity samples (20 IU/L, 10 IU/L, 5 IU/L, $2.5 \mathrm{IU} / \mathrm{L}$, and $0 \mathrm{IU} / \mathrm{L}$ ) from the ELISA Kit. Afterwards, telomerase activity of different cells (E-J, HeLa, and MCF-7) were evaluated by comparison with the standard curve. 


\section{Figures \& Tables}

\subsection{Mechanism Study}

Table S1. Oligonucleotides used in this study.

\begin{tabular}{cccc}
\hline Name & Sequence (5' to 3') & Length (nt) & Purify method \\
\hline \multirow{2}{*}{ QP } & (DABCYL)-AATCCG TCGAGC & 18 & HPLC \\
TP & AGAGTT & 18 & HPLC \\
NBD-primer & AATCCG TCGAGC AGAGTT & 18 & HPLC \\
Q-Ex-0 & (DABCYL)-CCGAAT AGCTCG & 18 & HPLC \\
SODN & GTTAGA & 11 & PAGE \\
ASODN & CTAACCCTAAC & 11 & PAGE \\
miR-21 & GTTAGGGTTAG & 22 & HPLC \\
\hline
\end{tabular}



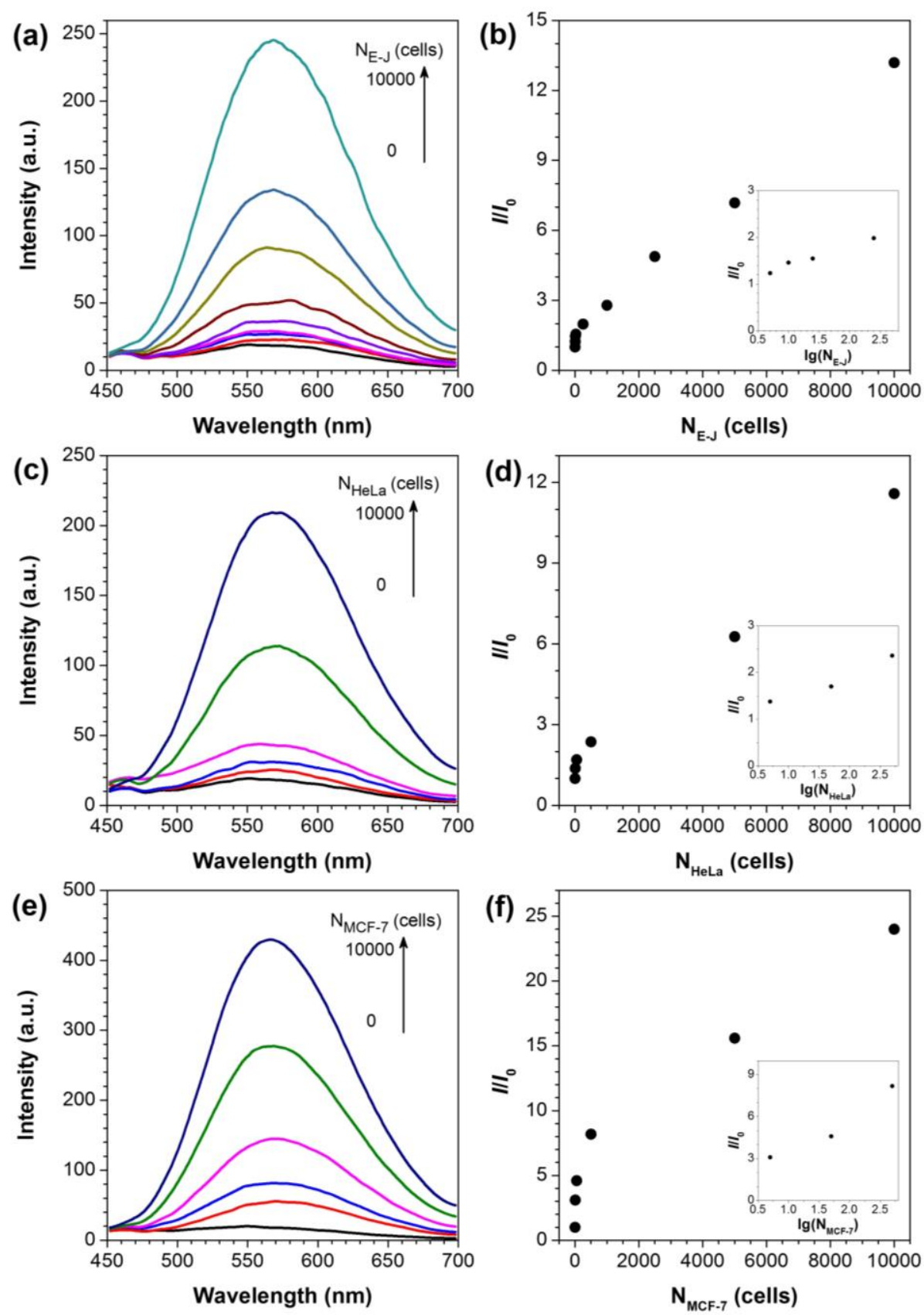

Figure S1. (a, c, e) Emission spectra of TPE-Py in response to telomerase extracts from different numbers of bladder cancer cells E-J (a), cervical cancer cells HeLa (c), and breast cancer cells MCF-7 (e). (b, d, f) The relationship between fluorescence enhancement and numbers of cancer cells E-J (b), HeLa (d), and MCF-7 (f). Insets: Relationship between fluorescence enhancement at $575 \mathrm{~nm}$ and the logarithm of cell numbers. 


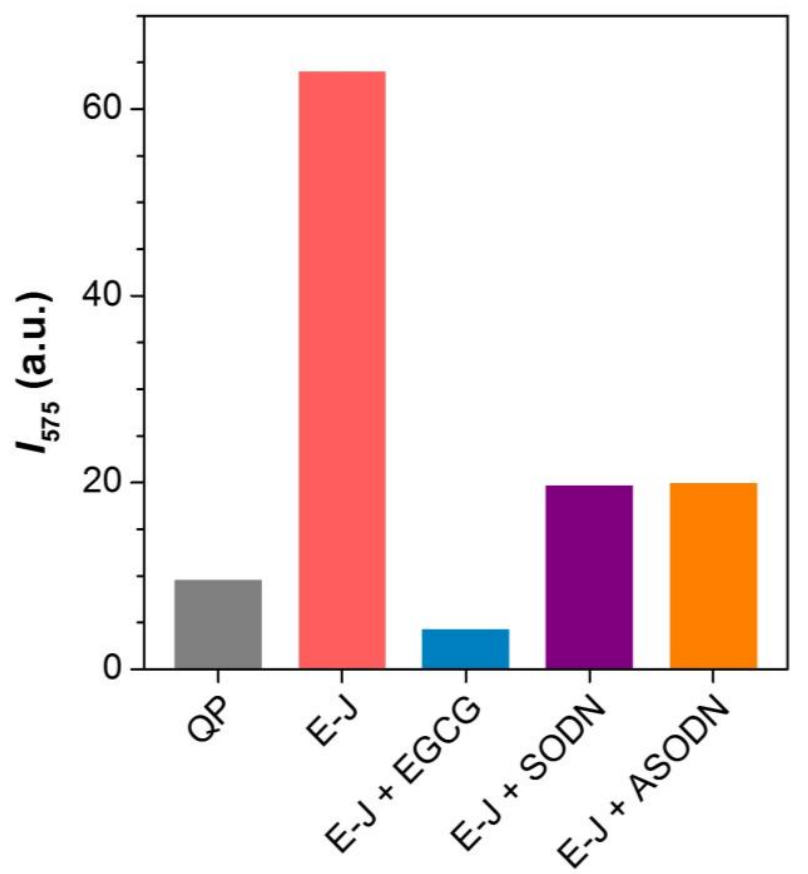

Figure S2. Inhibition of telomerase activity in extracts from 10000 E-J cells by $1 \mathrm{mM}$ EGCG, $0.5 \mu \mathrm{M}$ SODN, and $0.5 \mu \mathrm{M}$ ASODN. 

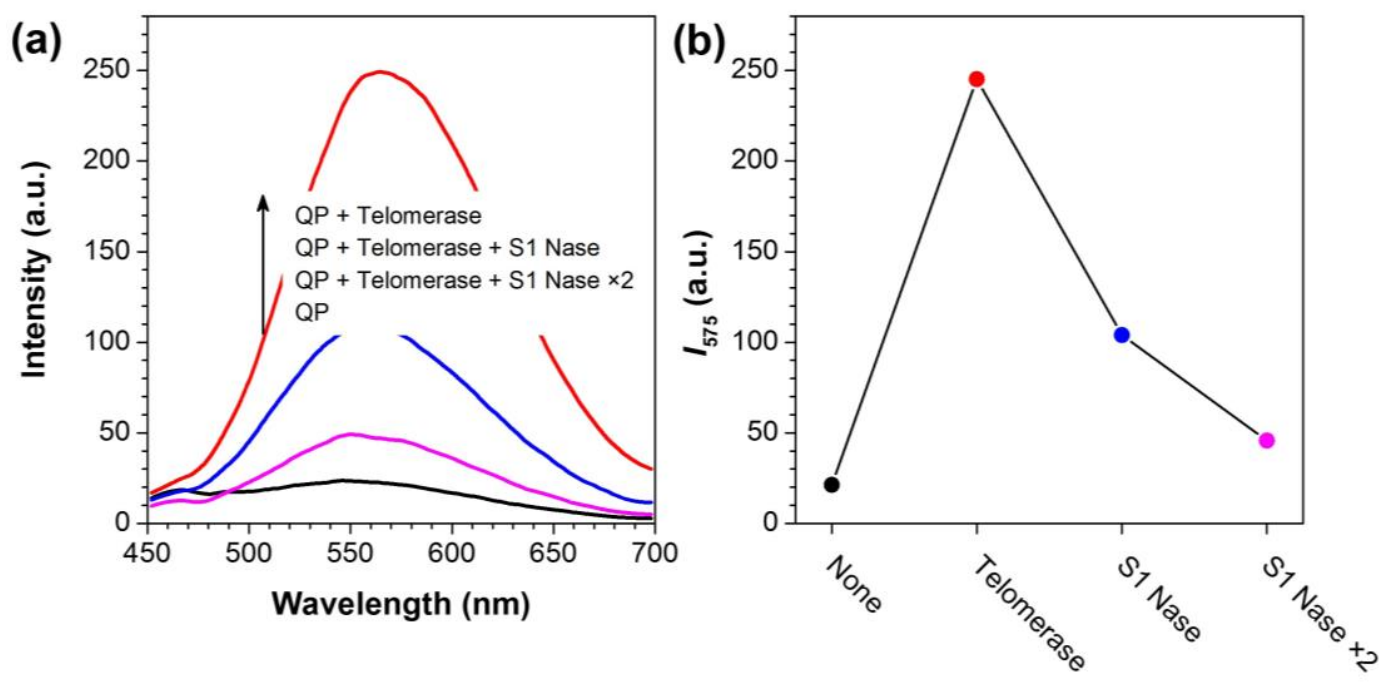

Figure S3. Working mechanism interpretation through DNA degradation caused by S1 Nase. (a) Fluorescence emission spectra of Silole only (black), Silole-R in the presence of elongated QP by telomerase extracted from E-J cancer cells without (red) and with 18 U S1 Nase (blue) or secondary 10 U S1 Nase (pink). (b) Plot of the changes in fluorescence intensity at $575 \mathrm{~nm}$ with telomerase, S1 Nase, and secondary S1 Nase, successively. 


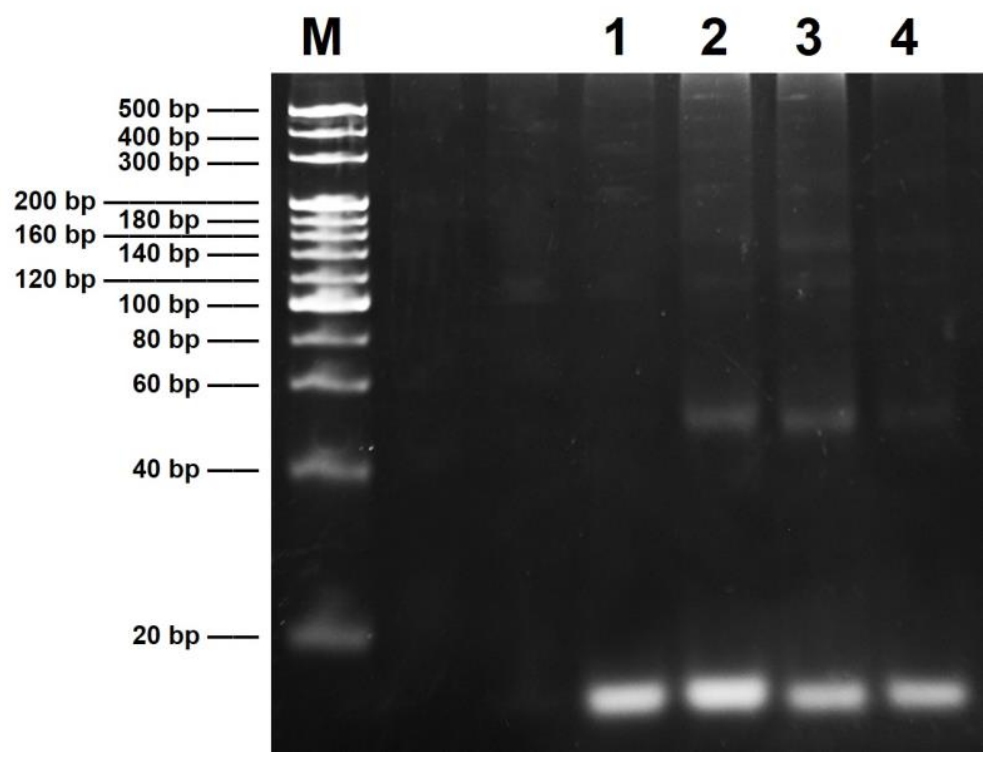

Figure S4. Non-denaturating PAGE analysis of this fluorescence assay: DNA ladder marker (lane M), QP in the absence (lane 1) and presence of telomerase extracted from 50000 E-J cancer cells (lane 2), 50000 MCF-7 cancer cells (lane 3) and 50000 HeLa cancer cells (lane 4). 

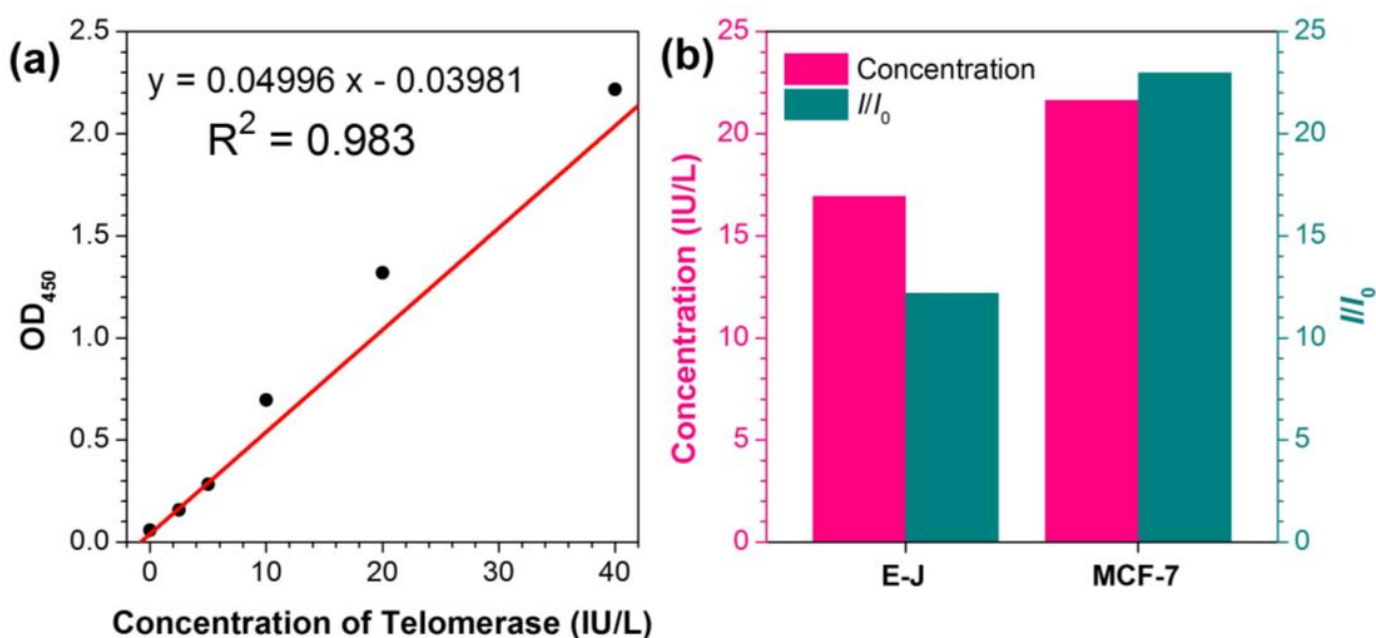

Figure S5. Mechanism study by a commercial human telomerase ELISA Kit. (a) Linear relationship in optical density (OD) at wavelength of $450 \mathrm{~nm}$ against standard telomerase at a concentration range of 0-20 IU/L. (b) Histogram for telomerase concentration (activity) obtained from commercial telomerase ELISA Kit and $I / I_{0}$ value of our method in detecting the activity of telomerase extracted from 10000 E-J and MCF-7 cells. 


\subsection{Transfection Verification}

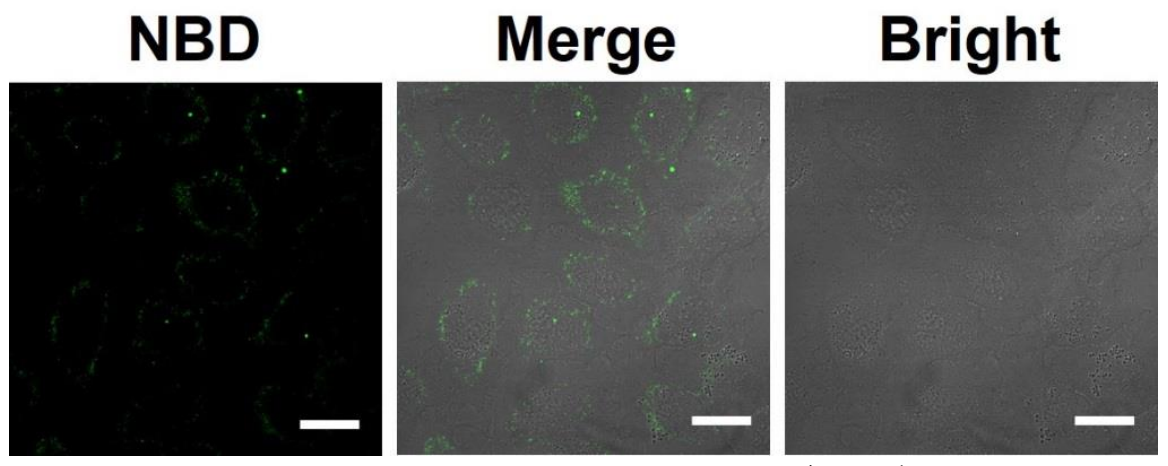

Figure S6. Confocal images of E-J cells $\left(0.5 \mathrm{~mL}, 4 \times 10^{4} \mathrm{~mL}^{-1}\right)$ after transfection with 3.6 $\mu \mathrm{M}$ NBD-primer for $1 \mathrm{~h}$. Scale bar: $20 \mu \mathrm{m}$. 


\subsection{In Situ Detection of Telomerase Activity}

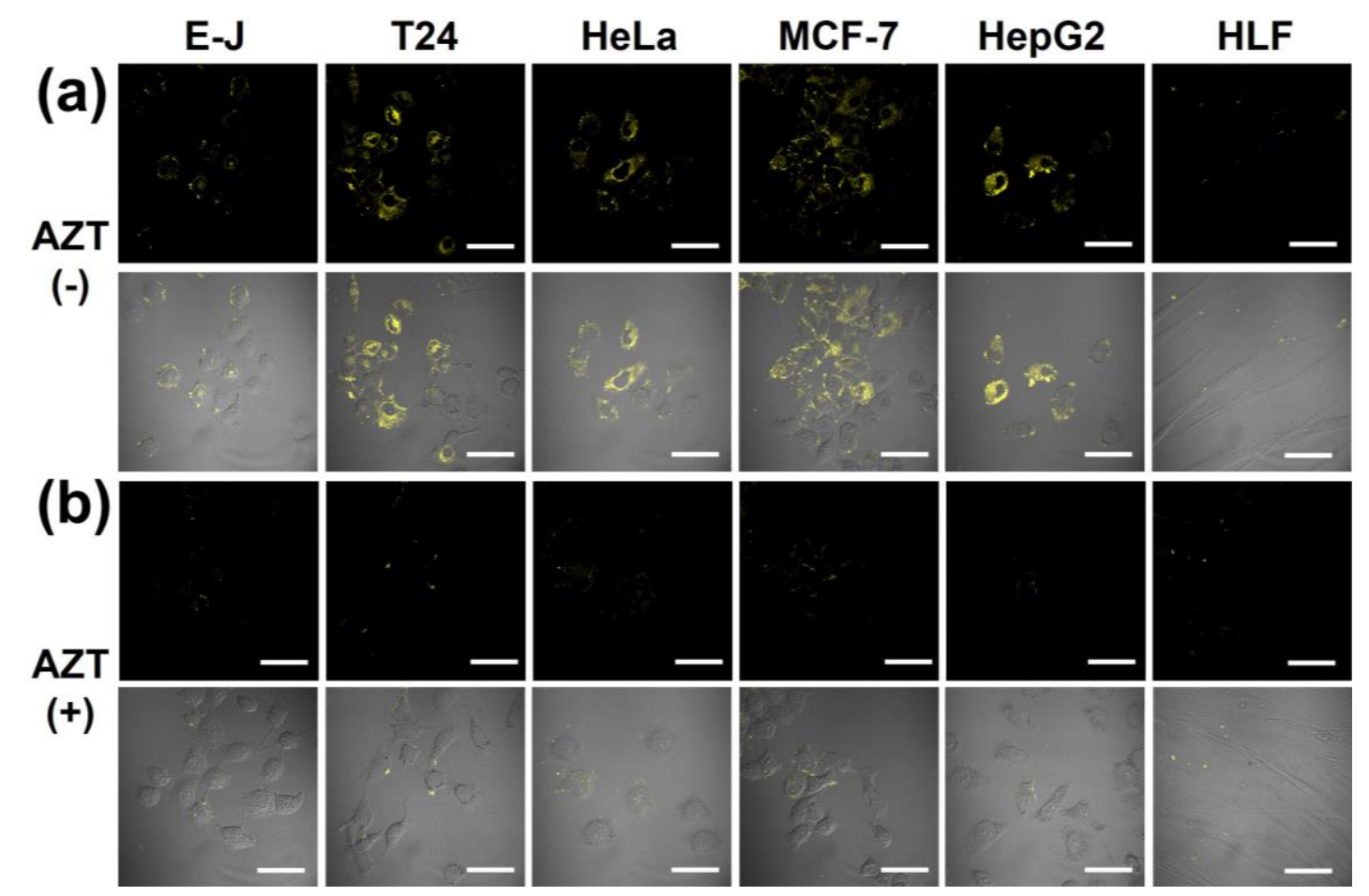

Figure S7. Fluorescence and merged images of parallel experiments as with Figure 2. Scale bar: $50 \mu \mathrm{m}$. 
Table S2. Fluorescence enhancement ratios in Figure 2 (using QP) of different cancer cells compared to AZT-treated cancer cells, normal cells HLF, and AZT-treated HLF, respectively.

\begin{tabular}{lccc}
\hline & \multicolumn{3}{c}{ Compared to } \\
\cline { 2 - 4 } & AZT-treated one & HLF & AZT-treated HLF \\
\hline E-J & 24.15 & 13.86 & 14.72 \\
T24 & 31.12 & 15.52 & 16.49 \\
HeLa & 11.16 & 12.33 & 13.10 \\
MCF-7 & 9.16 & 23.69 & 25.17 \\
HepG2 & 10.70 & 10.33 & 10.97 \\
\hline
\end{tabular}




\subsection{Photobleaching Telorance}

(a)

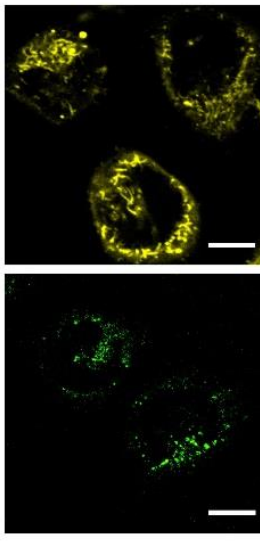

1 Scan

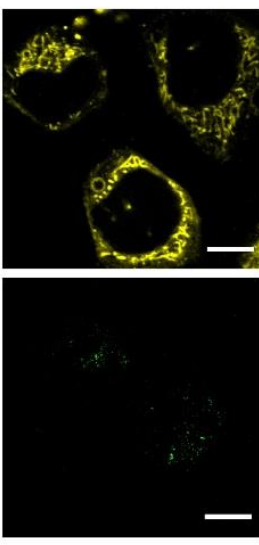

10 Scans

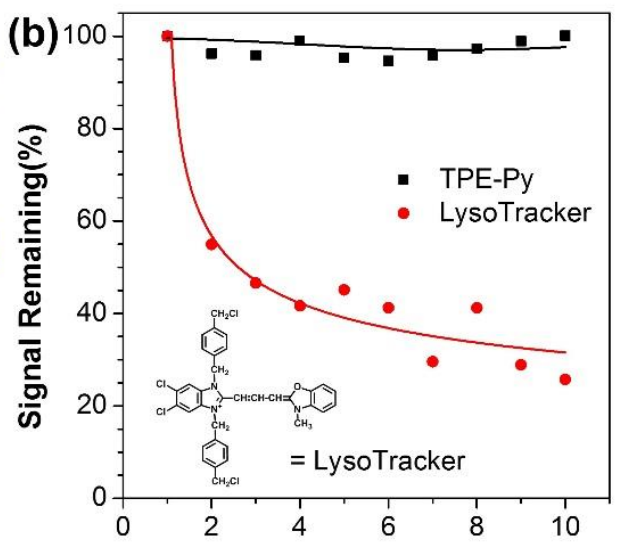

No. of Scan

Figure S8. (a) Time course of confocal images of E-J cells transfected with $3.6 \mu \mathrm{M}$ $\mathrm{QP}$ for $1 \mathrm{~h}$ and then incubated with $4 \mu \mathrm{M}$ TPE-Py (upper) or $50 \mathrm{nM}$ LysoTracker (under). Excitation wavelength: $405 \mathrm{~nm}$ (for TPE-Py) and $488 \mathrm{~nm}$ (for LysoTracker); emission filter: 525-625 nm (for TPE-Py) and 500-600 nm (for LysoTracker); irradiation time: $13.816 \mathrm{~s} / \mathrm{scan}$; scale bar: $50 \mu \mathrm{m}$. (b) Signal remaining (\%) of fluorescence intensity of TPE-Py (black square) and LysoTracker (red circle) in E-J cells with increasing number of scans. E-J cells were transfected with 3.6 $\mu \mathrm{M}$ QP for 1 $\mathrm{h}$ before stained. 


\subsection{In Situ Tracking of Intracellular Telomerase Activity Using}

Different Types of Cells

(a)

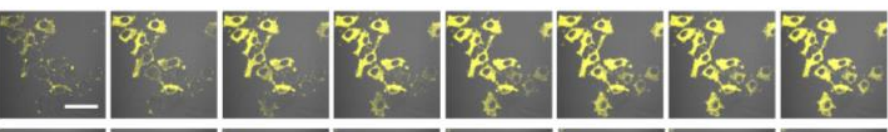

(b)
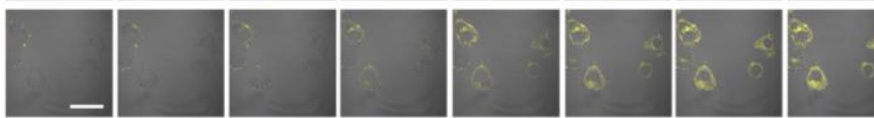

(c)

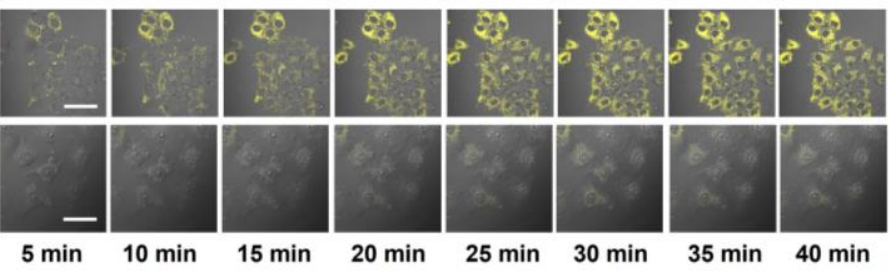

(e)

(e)

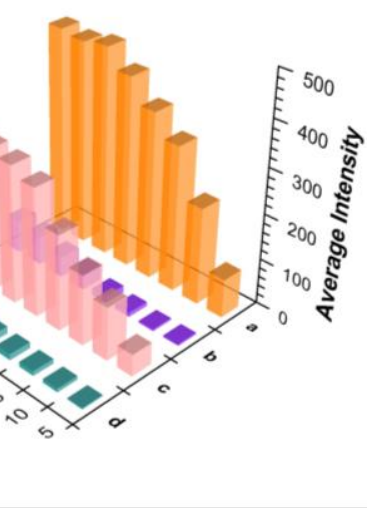

Figure S9. Time course of confocal merge images of MCF-7 cells. (a-d) Merged images of cells in Figure 3 with TPE-Py channels. Scale bar: $50 \mu \mathrm{m}$. (e) Changes in fluorescence intensity of MCF-7 cells shown in parts a-d with different time. 


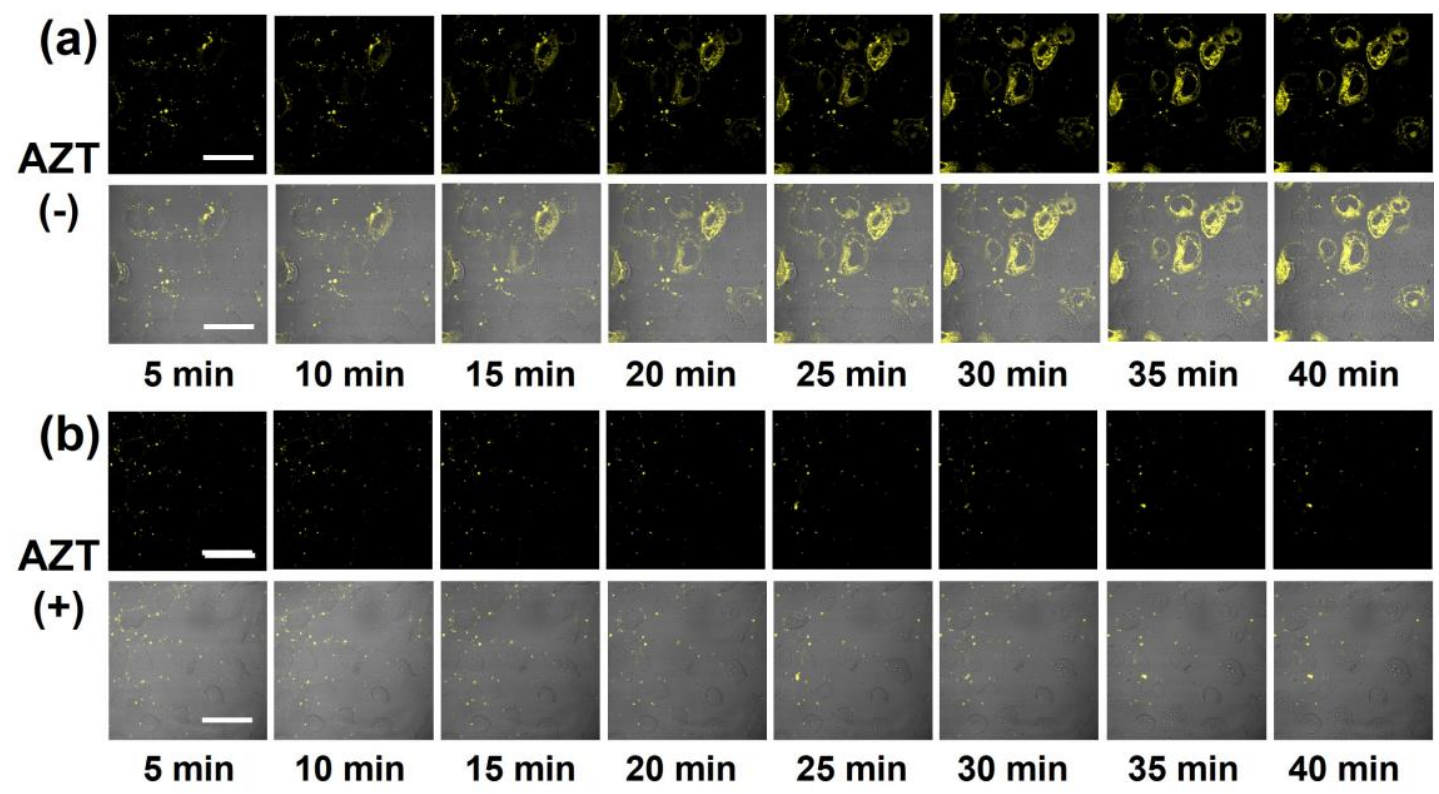

Figure S10. Time course of confocal images (fluorescence and merged) of E-J cells treated similarly as Figure $3 \mathrm{a}$ and 3b. Scale bar: $50 \mu \mathrm{m}$. 


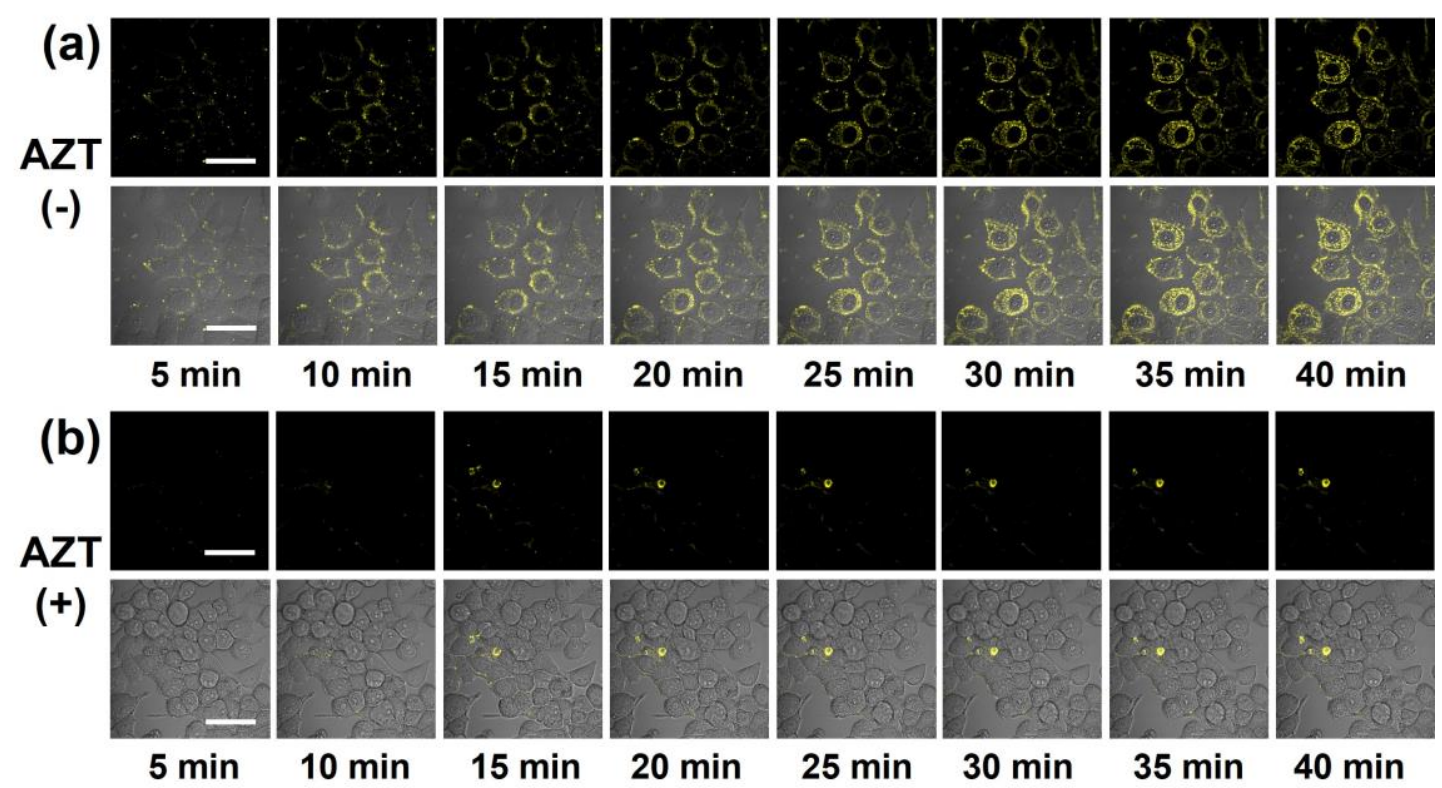

Figure S11. Time course of confocal images (fluorescence and merged) of HeLa cells treated similarly as Figure $3 \mathrm{a}$ and $3 \mathrm{~b}$. Scale bar: $50 \mu \mathrm{m}$. 


\subsection{Probe Stability and Intracellular Working Mechanism}

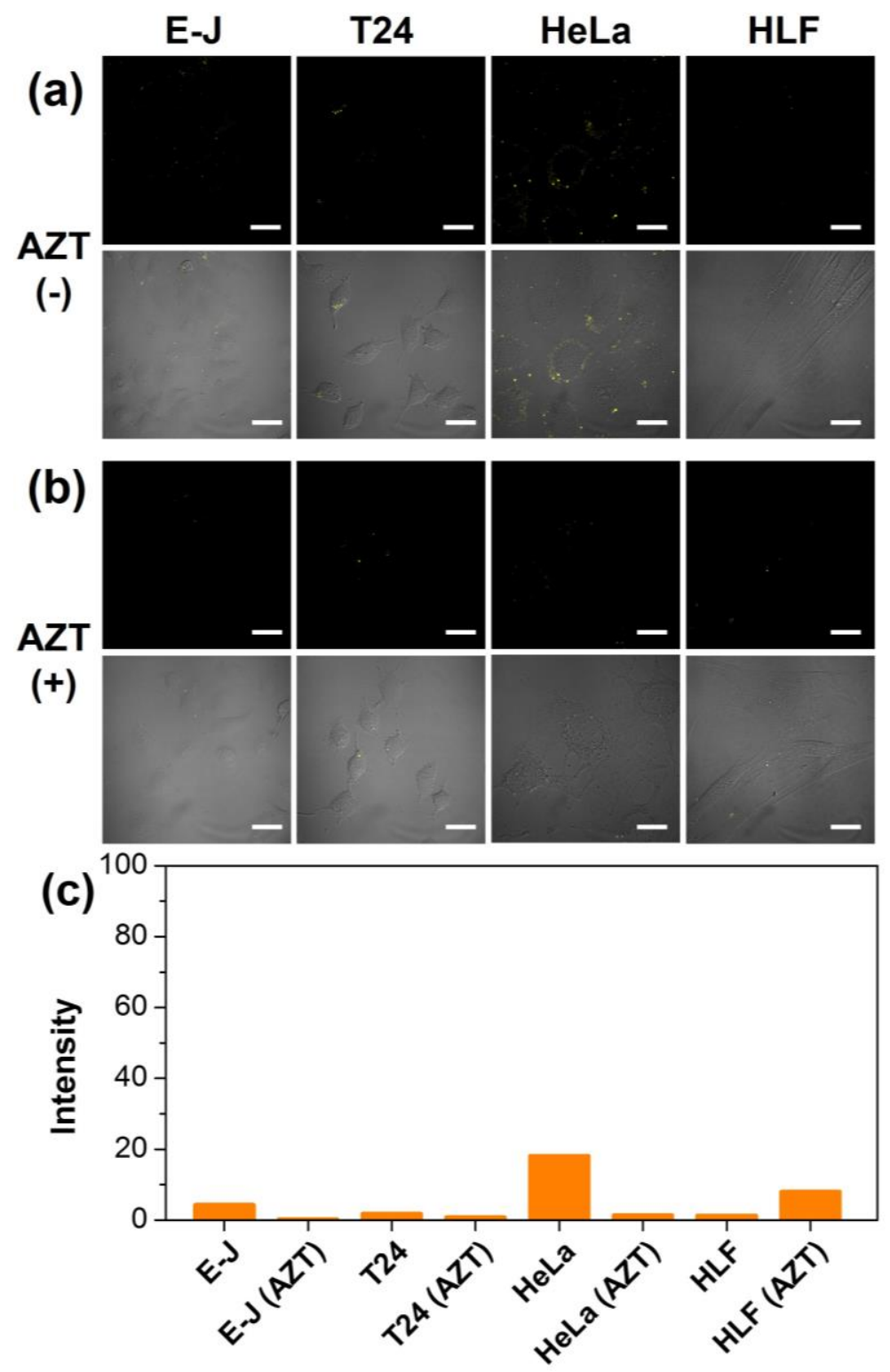

Figure S12. (a,b) Confocal images of E-J, T24, HeLa, and HLF cells $\left(0.5 \mathrm{~mL}, 4 \times 10^{4}\right.$ $\mathrm{mL}^{-1}$ ) after transfection with $3.6 \mu \mathrm{M}$ TP for $1 \mathrm{~h}$ and incubation with $6 \mu \mathrm{M}$ TPE-Py for 10 min. Cells were pretreated without (a) or with (b) $20 \mu \mathrm{M}$ AZT for $48 \mathrm{~h}$ before transfection. Scale bar: $20 \mu \mathrm{m}$. (c) Fluorescence intensity in different cells of parts a and $b$. 
Table S3. Fluorescence enhancement ratios (using TP) of different cancer cells compared to AZT-treated cancer cells, normal cells HLF, and AZT-treated HLF, respectively.

\begin{tabular}{lccc}
\hline & \multicolumn{3}{c}{ Compared to } \\
\cline { 2 - 4 } & AZT-treated one & HLF & AZT-treated HLF \\
\hline E-J & 16.45 & 3.33 & 0.54 \\
T24 & 2.22 & 1.36 & 0.22 \\
HeLa & 13.39 & 13.97 & 2.27 \\
\hline
\end{tabular}


(a)
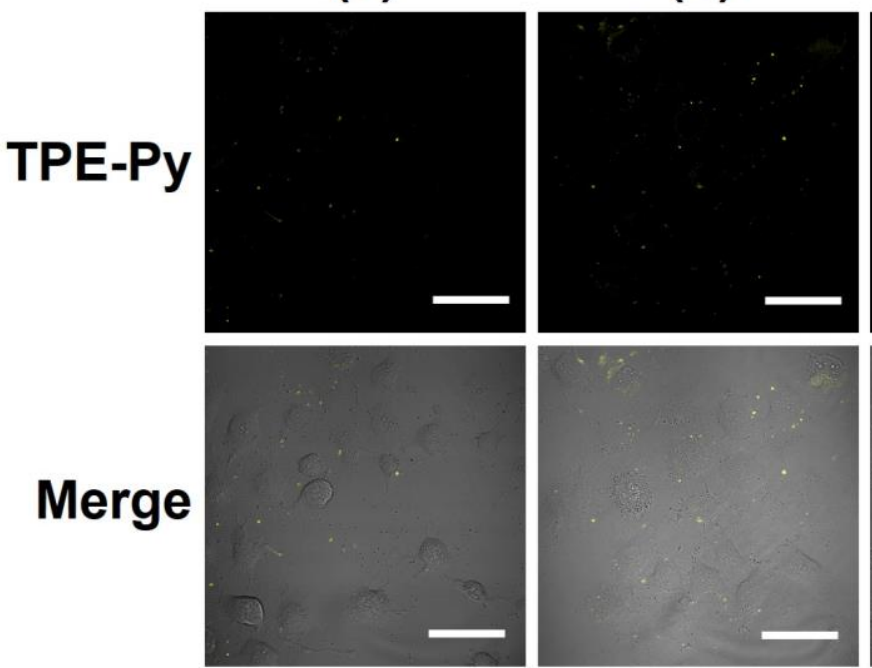

DNA Q-Ex-0 (b)
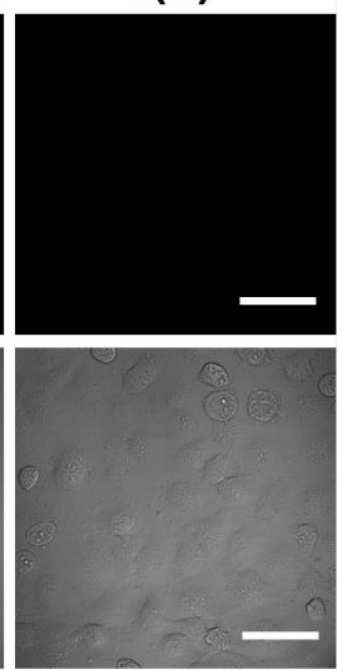

I (c)

\section{QP}

\section{TPE-Py $(\mu \mathrm{M})$}

6.0

6.0

0

Figure S13. Confocal images of E-J cells $\left(0.5 \mathrm{~mL}, 4 \times 10^{4} \mathrm{~mL}^{-1}\right)$ after (a) transfection with $3.6 \mu \mathrm{M}$ Q-Ex-0 for $1 \mathrm{~h}$ then incubation with $6 \mu \mathrm{M}$ TPE-Py for $10 \mathrm{~min}$; (b) only incubation with $6 \mu \mathrm{M}$ TPE-Py for $10 \mathrm{~min}$; (c) only transfection with $3.6 \mu \mathrm{M}$ QP for 1 h. Scale bar: $50 \mu \mathrm{m}$. 

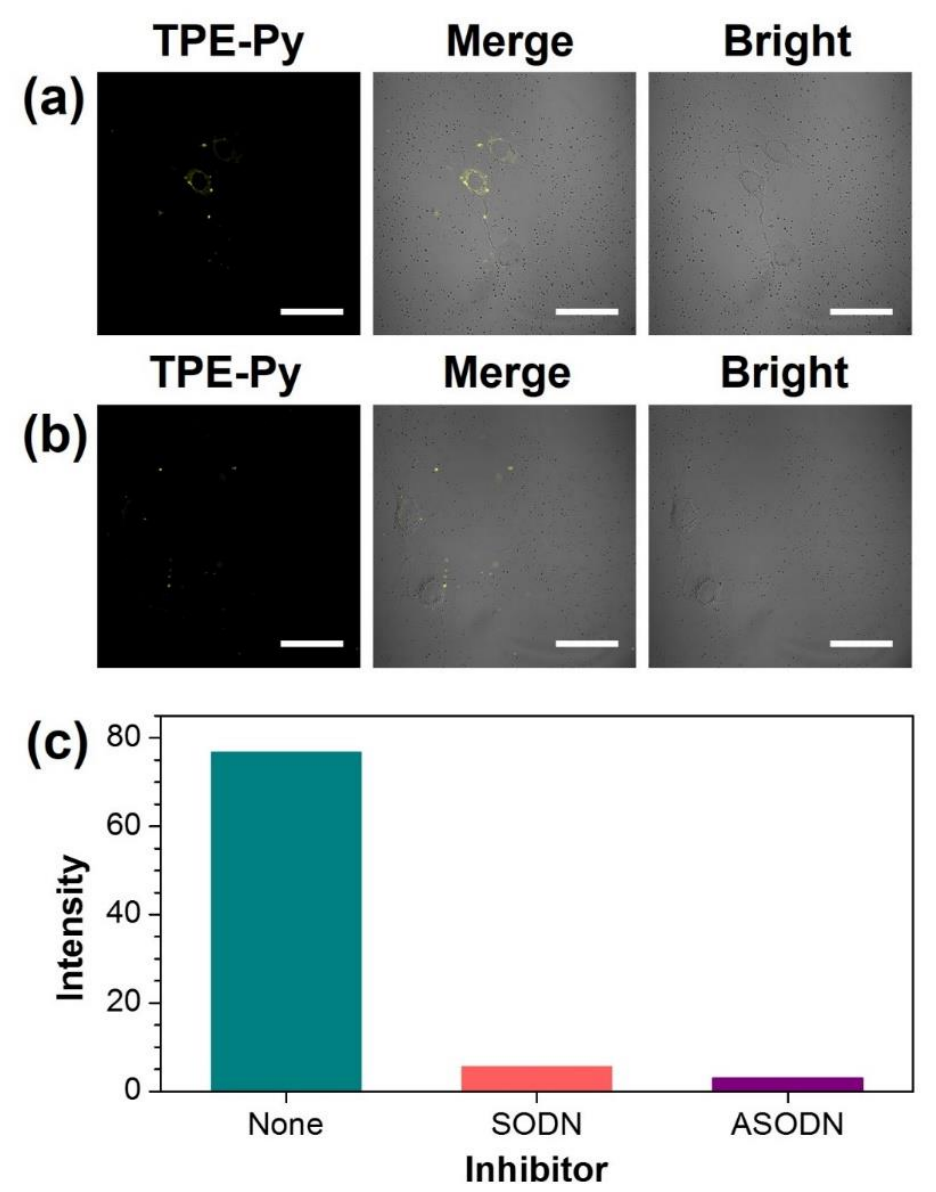

Figure S14. $(\mathrm{a}, \mathrm{b})$ Confocal images of E-J cells transfected with $3.6 \mu \mathrm{M}$ QP for $1 \mathrm{~h}$ and then incubated with $6 \mu \mathrm{M}$ TPE-Py for $10 \mathrm{~min}$. E-J cells were pretreated with 10 $\mu \mathrm{M}$ SODN (a) or $10 \mu \mathrm{M}$ ASODN (b) for $48 \mathrm{~h}$. Scale bar: $50 \mu \mathrm{m}$. (c) Fluorescence intensity of E-J cells pretreated with SODN and ASODN. 


\section{Reference}

(1) Zhao, N.; Li, M.; Yan, Y.; Lam, J. W. Y.; Zhang, Y.; Zhao, Y.; Wong, K. S.; Tang, B. Z. J. Mater. Chem. C 2013, 1, 4640-4646. 